\title{
Evaluating Marketing Strategies in Organ Donation and Transplantation
}

\author{
Peter Masibinyane Dimo ${ }^{1}$ \\ ${ }^{1}$ Department of Social Work, University of Zululand, South Africa \\ Correspondence: Peter Masibinyane Dimo, Department of Social Work, University of Zululand, Private Bag \\ X1001, KwaDlangezwa 3886, South Africa. Tel: 27-35-902-6664. E-mail: DimoP@unizulu.ac.za; \\ charismadimo@gmail.com
}

Received: May 28, 2019 Accepted: July 19, 2019 Online Published: August 31, 2019

doi:10.5539/gjhs.v11n10p160

URL: https://doi.org/10.5539/gjhs.v11n10p160

\begin{abstract}
Patients suffering from end-stage diseases wait in expectation of life-saving organs that could improve their quality of life. However, there is widening gap between organ supply and demand. The intention of this study is to explore and evaluate marketing strategies in organ donation and transplantation. In an attempt to achieve the purpose of this study, a qualitative approach was employed. Phenomenology was used as the study's research design. The study used social marketing and the theory of social constructivism as the theoretical frameworks and data was collected through in-depths interviews. Qualitative data was analysed through thematic content analysis. Purposive sampling was used to select 30 organ donation coordinators. The study established that public education is the main vehicle through which organ donation and transplantation are promoted. Educational talks, distribution of information, media, social media, expos, awareness events, and corporate and educational talks are amongst the strategies used to promote organ donation. The study recommends that the Department of Education include the issue organ donation in school curricula, and that religious organisations, regular worksite campaigns, regular television advertisements should be used as vehicles through which to promote organ donation and transplantation. Furthermore, it is recommended that additional public awareness campaigns be held in black communities. It is respectfully recommended that the Organ Donor Foundation consider opening satellite offices in all nine South African provinces.
\end{abstract}

Keywords: evaluation, marketing, organ donation

\section{Introduction and Background to the Study}

Organ donation is the greatest gift of love, and occurs when organ donors allows their vital body organ to be removed legally while they are still alive or after their death, with their next of kin's consent. Vital body organs that could be removed to save and prolong the lives of patients that are facing death are the heart, lungs, liver, kidneys, part of the pancreas, bone marrow, the skin, and part of the intestines. The majority of investigations into organ donation and transplantation reveal that people have positive attitudes regarding organ donation and transplantation. Nevertheless, there is no correlation between their attitudes and the number of people that are actually registered as prospective organ donors. The demand for human body organs always supersedes organ supply due to the lack of committed and registered organ donors. Organ donation is the only efficacious curative therapy for some end-stage diseases, and therefore it is fundamental to explore strategies that could expand the donor pool (Stiegler, Bausys, Leber, Strupas, \& Schemmer, 2018; Wong \& Chow, 2017). It is against this background that this study seeks to explore and evaluate marketing strategies that are used to expand the donor pool or raise the awareness about organ donation and transplantation.

\subsection{Problem Statement}

The acute shortage of human body organs for transplantation is a public health concern both in developed and developing countries. It is the ambition of health departments to close the widening gap between the demand and the supply of organs. However, it is widely acknowledged that organ demand is always greater than organ supply, due to the shortage of organ donors. South Africa has approximately 4,300 patients suffering from end-stage diseases, and organ donation is their only hope to save them from death and/or to improve and prolong their quality of life. Li, Garg, Prakash, Grimshaw, Taljaard, Mitchell, Matti, Linklater, Naylor, Dixon, Faulds, Bevan, Getchell, Knoll, Kim, Sontrop, Bjerre, Tong, and Presseau (2017) report that in 2013 approximately 4,400 patients in 
Canada were on a waiting list and unfortunately 246 died before they could receive a life-saving organ. Additionally, Queeley and Campbell (2018) also established that 678,000 Americans were suffering from end-stage renal failure, and it was estimated that patients suffering from end-stage renal disease (ESRD) might exceed 2,000,000 by 2030. It is important to view the extent of this problem with different lenses and from different angles in a holistic manner. Good health is an essential aim for people since without good health people are unable to play their roles in developing their country's economies. If they are in bad health, they become the liability of the state, as many of them might not be able to afford the high medical costs that are associated with ESRD. Furthermore, family life as a system is disrupted by family members facing the reality of their loved one's death as a result of the chronic shortage of vital body organs available for transplantation.

The medical transplantation of organs cannot take place without the organ donors' availability and the commitment. To add to the difficult circumstances of hopeless patients, the Organ Donation Foundation (2019) reported that only $0.2 \%$ of South Africans are registered as organ donors, and this adds to the situation that both public and private hospitals cannot guarantee that they will be able to harvest organs from this minute pool of organ donors. This claim is based on the fact that many countries like South Africa use the opt-in system of organ donation where family consent is necessary for organs to be harvested from their deceased family members. According to Bhatia and Tibballs (2017), individuals voluntarily register to donate their vital organs after death. According to Sharif and Moorlock (2018) it is challenging to obtain consent from the deceased organ donor's next-of-kin or close family members. These authors argue that failure to obtain consent is a barrier to organ donation because the volume of people who decline consent is significantly high and this is an insurmountable obstacle to overcome, as procurement of organs cannot be made without valid consent. In medical social work organ donation consent is called the self-determination principle and this is the cornerstone of ethical social work practice. This principle provides clients with the democratic right to make their own decisions as medical doctors, professional nurses, social workers, and organ donation coordinators may not coerce them into giving consent. The opt-in system of organ donation considers organ donation as an act of generosity or an altruistic act because prospective organ donors are not legally compelled to donate their life-saving organs such as the heart, kidneys, liver, and pancreas. This kind of system is democratic and it is based on the fundamental human rights as they are enshrined in the Constitution of the Republic of South Africa, which is regarded as the country's supreme law.

However, under this opt-in system it is difficult to close the gap between organ supply and demand. There was mounting pressure to introduce the opt-out system of organ donation in Australia because it is considered to be the panacea that will remedy the chronic shortage of organs. However, despite these many pleas to introduce the system, the request was not granted. The acute organ shortage is caused by multifarious factors. Amongst the factors that hinder people from participating in organ donation are a lack of or insufficient information about organ donation as well as socio-cultural factors. Sukalla, Wagner, and Rackow (2017) support these views and assert that people's reluctance to become organ donors or to consent to organ donation is caused by a lack of knowledge and misinformation regarding brain death, as well as religious norms. Although a lack of information is considered to be the main barrier to organ donation, Krupic, Sayed-Noor, and Fatahi (2016) further argue that limited information from healthcare professionals such as medical social workers, nurses, and doctors is an impediment to organ donation as they have to shoulder the responsibility of making people aware of organ donation and transplantation and some of them are not in favour of organ donation. The general public seems to have generally positive attitudes towards organ donation and transplantation, nevertheless there seems to be no correlation between people's attitudes and the supply of organs. The majority of studies on organ donation continue to cite religion as a deterrent to organ donation and transplantation. These are Williamson, Reynolds-Tylus, Quick, and Shuck's (2017) views, and they state that people are concerned about the integrity of the body and life after death due to their religious beliefs. This is accompanied by factors such as superstition and the fear of donation. This study seeks to answer this question:

- What are the strategies that are used to promote organ donation?

\section{Research Methodology}

Research methodology refers to the scientific research procedures and techniques that researchers use to identify, select, process, and analyse data about the phenomenon under investigation. In this study the research methodology included the research approach, design, type of research, population, sampling, data collection, theoretical frameworks, and ethical considerations. Furthermore, this study's methodology was influenced by the study's goal.

\subsection{Research Approach}

This study's intention was achieved by using a qualitative approach. This was an appropriate approach because it is 
intense, engaging, challenging, contextualised, and highly variable (Gray, 2018). In addition to this view, Taylor, Killick, and Mcglade (2015) claim that a qualitative approach is appropriate when the research goal is to explore the meanings, perceptions, and constructs in real world contexts, particularly where there is extremely limited information about the subject under investigation. This study's goal was to engage organ donation coordinators in analysing existing organ donation marketing strategies and to explore efficacious marketing strategies that can be used to improve the status of organ donation and transplantation in South Africa. Whittaker (2012) adds that qualitative studies tend to utilise data in the form of words rather than quantifying the information.

\subsection{Research Design}

This study adopted phenomenology and a case study as its research design. The majority of researchers describe a research design as a study's blueprint, and according De Vos, Strydom, Fouche, and Delport (2011), research design is seen as those decisions that scientific researchers make when planning their investigations. Babbie and Mouton (2001) support this definition and state that the purpose of research design is to address the planning of scientific investigations. Organ donation coordinators currently shoulder the responsibility of raising public awareness about organ donation and transplantation, recruiting donors, and obtaining informed consent. Therefore, the phenomenology and case study methods were appropriate. Firstly because this study's purpose was to explore and evaluate marketing strategies used to raise the awareness about organ donation and transplantation. Secondly, the intention was to elicit the organ donation coordinators' views and experiences in using those strategies. According to Padgett (2008) phenomenological studies seek to explore the lived experiences of a phenomenon. This view finds its support in Creswell, Ebersohn, Eloff, Ferreira, Ivankova, Jansen, Nieuwenhuis, Piterson, and Clark (2016), who maintain that all phenomenological investigations are explorations into the structures of the human life-world and lived experiences, as experienced in everyday situations and relations.

\subsection{Type of Research}

Scientific investigations are conducted in order to generate new knowledge and to update available knowledge. In addition to this purpose, scientific studies are done in order to solve problems that affect individuals, groups, and communities. This study is classified as basic research because its intention was to evaluate existing organ donation strategies and to explore and recommend more effective marketing strategies that could be used to increase awareness in organ donation and transplantation, which will result in a high volume of organ donors. According to Brynard, Hanekom, and Brynard (2014), basic research is used to increase knowledge in a particular field.

\subsection{Population}

A population in scientific investigations refers to a group of people that have specific features that are of interest to the researcher (Brynard et al., 2014). Brink, Van der Walt, and Van Rensburg (2012) support this view and define a research population as the entire group of people in a particular geographical location that is of interest to the researcher. For the purpose of this study, organ donation and transplant coordinators were the unit of analysis. The study targeted those subjects who had more than three years experience as organ donation and transplant coordinators

\subsection{Sampling}

In qualitative studies sampling is done through non-probability sampling techniques. In this study, both the purposive and snowball techniques were used to select 30 participants who had more than three years' working experience in the field of organ donation and transplantation. Shaw and Holland (2014) are of the view that purposive sampling is used when people, settings, and context are chosen simply because they constitute typical cases or extreme cases. According to Creswell et al. (2016), purposive sampling is done with a specific purpose in mind. Furthermore, the researcher should be knowledgeable about the population under investigation. Snowballing was used to identify inaccessible research participants. De Vos et al. (2011) assert that snowball sampling is normally used when a researcher has limited access to appropriate participants for the intended investigation.

\subsection{Data Collection}

Interviews are a dominant method of collecting data in social work practice. Non-directive interviews were used to collect data, and all interviews were conducted in an environment conducive to ethical data collection. According to Gray (2018), non-directive interviews are appropriate to explore issues or topics in depth. An additional advantage of non-directive interviews is that research questions are not pre-planned. 


\subsection{Theoretical Frameworks}

Different theoretical frameworks are used to view, understand, and analyse diverse social problems that affect people (Fox, Martin, \& Green, 2007). This study adopted social marketing and the theory of social constructivism as its theoretical frameworks. Organ donation and transplantation are highly controversial and emotive subjects. Furthermore, it is a subject that is misunderstood and it not many people want to discuss it. Social marketing is based on the assumption that a community's effective social functioning is determined by their social attitudes and concomitant behaviour, and it is believed that their behaviour can be changed by employing principles that are used to sell commercial goods and services (Weyers, 2011). According to Pereira, Velese e Sousa, Shigaki, and Lara (2018), social marketing can be considered to be the conception, implementation, control, and monitoring of a programme that is aimed at influencing a social idea's acceptability. It is evident, based on the above two definitions that social marketing's goal is to influence the targeted audience to accept information voluntarily, and to modify their behaviour for the benefit of other people. This study further argues that knowledge precedes action in organ donation. The majority of studies in organ donation, both locally and internationally, cite the lack of knowledge as a barrier to organ donation. The decisions that people take are hugely influenced by the knowledge that they have. In addition to this view, it is important to accept the fact that people possess information that is misleading or inaccurate. Therefore, it is fundamental to explore how people learn about organ donation and transplantation. According to the theory of social constructivism, people generate knowledge through their interactions. The theory of social constructivism is a theory of knowledge of sociology and communication that assesses the development of a jointly constructed understanding of the world. It is defined as a perspective that purports that a great deal of human life exists as it does due to social and interpersonal influences.

\subsection{Ethical Considerations}

The aim of research ethics is to protect research participants physically, psychologically, and emotionally, particularly in qualitative methods due to the interactions between the researcher and participants. These views find their support in Shaw and Holland (2014) who declare that research ethics are concerned with protecting the participants' interests and safety of as well as those of other people who might be affected by the research. Padgett (2008) articulates that qualitative studies have an inherently strong appeal for social workers because they are driven by a professional relationship or a rapport. In this study, all participants signed an informed consent for to legally indicate their willingness to participate in the study. The informed consent form clearly indicated the study's purpose and the benefits and risks of participating in the study. Moreover, all participants were made aware that participation in the study was strictly voluntary. Participants were not coerced to participate in the study. They were given an opportunity to withdraw from the study if they felt uncomfortable. All interviews were conducted in a safe environment that promoted the participants' physical, psychological, and emotional safety. Furthermore, permission to conduct this study was granted by the University of Zululand's Higher Degrees and Ethics Committee. Confidentiality in social work practice and social work education is based on preserving confidential information concerning social workers' clients, information that is disclosed in the course of a professional interaction. In addition to this view, confidentiality in social work practice is based on the clients' rights, because social work is a human rights profession. Electronic information was kept in a password-protected computer, which was only known to the researcher, and field notes were kept in a locked cabinet at all times. The participants' contributions cannot be linked to them because their identifying information was not used in the report or in the field notes. Pseudonyms and numbers were used to identify participants. Lastly, the Department of Health granted permission to collect data.

\subsection{Data Analysis}

According to Taylor et al. (2015), all qualitative methods seek to understand people's words and behaviours rather than measuring or counting something, as in quantitative methods. For the purpose of this study, qualitative data was analysed through thematic content analysis.

\section{Results}

Health professionals are entrusted with the responsibility of making the general public aware of organ donation and transplantation, in order to recruit and retain prospective organ donors. In addition to this, they also shoulder the significant responsibility of obtaining consent from grieving families. The Organ Donor Foundation is the main vehicle used to make the public aware about organ donation and transplantation in South Africa via hospital-based organ donation programmes, and organ donation coordinators are involved in the difficult task of recruiting donors across the world. This study established that public education and education talks are still the dominant methods of raising awareness about organ donation in South Africa. Other methods that are used to market and promote organ donation and transplantation are the media (television), social media (Facebook), expos, awareness events, and 
corporate educational talks.

\section{Discussions of Findings or Results}

This study adopted the social marketing perspective and the theory of social constructivism as its theoretical frameworks and as a result the findings of this study are analysed from the perspective of these two theories. Public education is still the dominant marketing strategy used to promote organ donation and transplantation in South Africa. Organ donation and transplantation are not totally new concepts in South Africa, as the first heart transplant was performed in South Africa. Nevertheless, a plethora of scientific investigations nationally and globally continue to identify lack information regarding organ donation as a barrier that prevents people from participating in organ donation. Thomson (2017) supports this study's findings and reports that in South Africa, the organ donation rate is very low due to multiple factors. Firstly, there is a lack of awareness and knowledge among the public and medical professionals about brain death and organ donation. The lack of information on organ donation has disastrous consequences, as Thompson (2017) reports that in 2017 only 18\% of family members gave their consent medical professionals to the harvest their deceased family members' vital body organs in comparison to the staggeringly high 82\% that declined to give consent. According to Miller and Breakwell (2018), approximately 1,200 people miss out on a potentially life-saving transplant every year because of families that refuse to grant consent, while it important to remember that it only $0.2 \%$ of South Africans are registered as organ donors. This is an indication that public education does not produce the desired results, and furthermore, it is unable to close the widening gap between organ demand and supply, as Miller and Breakwell (2018) claim that the high demand for transplantable organs is not met by either the supply of live or deceased organ donors. Poor understanding of neurological death is another of the factors associated with the lack of information on organ donation. In medicine, neurological death is defined as the irreversible loss of capacity for consciousness, which is combined with the irreversible condition of being unable to breath. In support of this definition Krekula, Forinder, and Tibell (2018) state that neurological death is when the brain has lost totally all brain functions irreversibly, and this is the criterion for neurological death. It essential to understand that neurological death is the legal pre-requisite for organ donation, however neurological death is a subject that is highly misunderstood and tremendously controversial.

The second theme that emerged from the qualitative interviews is television. Television is a source of knowledge for many people in South Africa, particularly young people. Although television is used predominantly for entertainment purposes; it is also a powerful tool to disseminate information that can result in behavioural change. New research from Dataxis indicates that the total number of South African television-owning households will grow by $10 \%$ between 2015 and 2018, and it is estimated that the total number will be approximately 13.3 million (Editorial news television, 2016 October). The advantage of educating people through television is that you are able to target multitudes of people within a short period of time. Morgan, King, Smith, and Ivic (2010:780) discovered that viewing organ donation on television directly affects viewers' beliefs about organ donation. This observation is supported by Felley and Vincent (2007) as cited in Yoo and Tian (2011:157), who report that media sources have positive and negative effects on organ donation. Nevertheless, television is not an interactive educational tool because people are unable to ask questions that they have about organ donation and transplantation. The researcher further argues that the impact of organ donation messages can be determined by the frequency of messages about organ donation and also the times during which messages about organ donation appear on the television, as it extremely rare to see organ donation and transplantation marketing on television in South Africa due to the financial costs associated with television advertising, especially during peak viewing periods.

This study established that organ donation and transplantation is marketed through social networks such as Facebook. Al-Azawei (2018) defines social networking media as, "a group of Internet-based applications that build on the ideological and technological foundations of Web 2.0, and allow the creation and exchange of user generated content." It is undisputed that Facebook is the most popular social networking site in South Africa, followed by YouTube and Twitter (Shava \& Chinyamurindi, 2018), because in 2014 there were approximately 1.3 billion Facebook users. According to Nigam and Malik (2018), social networking sites such as Facebook provide a platform where internet users are at liberty to exchange their thoughts on different subjects, and in addition to this advantage, social networks are easy to search, they are community-based, and users can create communities that are based on their interests. In addition to these views, the researcher perceives Facebook as a tool that is capable of rapidly disseminating information, however it is more suited to a younger generation and excludes elderly citizens, particularly those who cannot read and write. In support of this view, Mo, Zhou, Kosinski, and Stillwell (2018) declare that elderly people have strong communication needs, but they are typically timid about using technologies that are easily navigable by younger generations but new and intimidating for them. The disadvantage of 
depending on Facebook as an instrument of raising the awareness about organ donation and transplantation is that people might provide misleading information, which could generate fear, mistrust, and result in myths being transmitted. It is advisable to monitor discussions closely, and all deliberations should be facilitated by experts in the field of organ donation and transplantation. The major limitation of using Facebook to raise awareness about organ donation is access to the internet and the financial costs that are associated with it. In comparison to other countries, data is expensive in South Africa, and the majority of internet users are young people who are significantly affected by unemployment. The majority of participants also identified expo events as a means of promoting organ donation and transplantation. Expo events are highly recommended because they are interactive in nature, and they encourage the general public to raise sensitive questions that bother them about organ donation. However, according to Symvoulakis, Markaki, Anyfantakis, and Rachiotis (2018), public awareness campaigns for organ donation and transplantation have yielded mixed results, indicating a growing need for culturally tailored and issue-targeted media campaigns. Their argument is based on the fact that organ donation and transplantation perceptions are embedded in socio-cultural factors and it is therefore vital to approach public awareness campaigns with a culturally tailored approach.

\section{Conclusions of the Study}

Organ donation and transplantation are one of the major public health concerns confronting South Africa, and as result, patients suffering from end-stage diseases have little hope of securing an organ due to the acute shortage of organ donors and thus available organs. There is no correlation between the supply and the demand of vital body organs. In a quest to close the gap between organ supply and demand, public education, television, social networks such Facebook, and educational campaigns are used to increase the donor pool. Nevertheless, this study does not dispute the fact that these strategies do have an impact but they do not result in the expected outcomes necessary to address the current situation, and this has catastrophic repercussions. South Africa has only $0.2 \%$ of registered organ donors and 4,300 patients are suffering from end-stage diseases.

\section{Recommendations of the Study}

Based on this study's findings, which are also mentioned in the study's conclusion, the following recommendations are made by the study.

Organ donation and transplantation is an under-researched subject in South Africa. The study recommends further research should be done. South Africa adopts the opt-in model of organ donation, and as a result is unable to close the widening gap between the demand and the actual supply of vital body organs. The opt-in model requires prospective organ donors to register to donate their organs after their deaths. According to the opt-in model, organ donation is viewed as an altruistic act. The study recommends that the Ministry of Health consider adopting the opt-out model of organ donation. This is a model that has been successfully adopted by Spain, which has a high volume of organ donors. However, according to the opt-out model of organ donation the procurement of vital body organs or tissues is performed routinely after the death of potential organ donors, unless a person has made a formal request prior to their death that their organs not be harvested. According to Li and Nikolka (2016), the opt-out model of organ donation reflects a presumed consent policy because all people are classified as potential organ donors. According to Rodriguez-Arias and Morgan (2016), the majority of countries that have adopted the opt-out model of organ donation have higher rates of organ donors.

Public education and awareness campaigns are not out-dated strategies of raising awareness about organ donation and transplantation, rather they are less costly and they have the potential to reach a higher volume of people. Nevertheless, the promotion of organ donation should take into consideration the contexts within which organ donation and transplantation are promoted. Organ donation and transplantation are influenced by socio-cultural factors and it is therefore essential to design awareness campaigns that are culturally tailored to diverse contexts. It is further recommended that educational talks, campaigns, and public education be held regularly and that rural areas are targeted. The subject of organ donation and the transplantation of body organs should take place in as young audiences as is possible, and organ donation and transplantation should be included in school curricula, particularly life orientation lessons. The rationale behind this suggestion is that children and young adults are typically assumed to less prejudicial and it is easier to teach them new concepts. This could enhance the promotion of organ donation as these learners are likely to discuss organ donation and transplantation with their parents and peers, and as a result, create a population and communities that are informed about organ donation. It also recommended that organ donation be promoted regularly through worksite campaigns. Worksite campaigns are important and useful because they provide a large captive audience that might be difficult to reach through other channels. 


\section{Competing Interests Statement}

The authors declare that there are no competing or potential conflicts of interest.

\section{References}

Al-Azawei, A. (2018). Predicting the adoption of social media: An integrated model and empirical study on Facebook usage. Interdisciplinary Journal of Information, Knowledge, and Management, 13, 233-238. https://doi.org/10.28945/4106

Babbie, E., \& Mouton, J. (2001). The Practice of Social Research: South African Edition. Cape Town: Oxford University Press.

Bhatia, N., \& Tibballs, J. (2017). The Development of Property Rights over Cadaveric Tissues and Organs: Legal Obstructions to the Procurement of Organs in an "Opt-Out" System of Organ Donation in Australia and New Zealand.

Brink, H., Van der Walt, C., \& Van Rensburg, G. (2012). Fundamentals of Research Methodology for Healthcare Professionals (3rd ed.). Cape Town, South Africa: Juta.

Brynard, D. J., Hanekom, S. X., \& Brynard, P. A. (2014). Introduction to Research (3rd ed.). Pretoria: Van Schaik.

Creswell, J.W., Ebersohn, L., Eloff, I., Ferreira, R., Ivankova, N. V., Jansen, J. D., .. \& Clark, V. L. P. (2016). First Steps in Research (2nd ed.). Pretoria: Van Schaik.

De Vos, A. S., Strydom, H., Fouche, C. B., \& Delport, C. S. L. (2011). Research at Grass Roots for the Social Sciences and Human Service Professions (4th ed.). Pretoria: Van Schaik.

Editorial news television. (2016 October).

Fox, M., Martin, P., \& Green, G. (2007). Doing Practitioner Research. London: Sage. https://doi.org/10.4135/9781849208994

Gray, D. E. (2018). Doing Research in the Real World (4th ed.). London: Sage.

Krekula, L.G., Forinder, U. \& Tibell, N. (2018). What Do People Agree To When Stating Willingness to Donate? On the Medical Interventions Enabling Organ Donation after Death. Plos one, 24 (2018), 3-17.

Krupic, F., Sayed-Noor, A. S., \& Fatahi, N. (2016). The Impact of Knowledge and Religion on Organ Donation As Seen By Immigrants in Sweden. Scandinavian Journal of Caring Sciences, 2017(31), 687-694. https://doi.org/10.1111/scs.12379

Li, J., \& Nikolta, T. (2016). The Effect of Presumed Consent Defaults on Organ Donation. Cefifo Dice Report, $4(2016), 90-93$.

Li, A. H., Garg, A. X., Prakash, V., Grimshaw, J. M., Taljaard, M., Mitchell, J., ... Presseau, J. (2017). Promoting Deceased Organ and Tissue Donation Registration in Family Physician Waiting Rooms (Registernow-1 Trial): Study Protocol for a Pragmatic, Stepped-Wedge, Cluster Randomized Controlled Registry. Bio Medical Central, 2017(18), 1-13. https://doi.org/10.1186/s13063-017-2333-5

Miller, C., \& Breakwell, R. (2018). What Factors Influence a Family's Decision to Agree to Organ Donation? A Critical Literature Review. London Journal of Primary Care, 10(4), 103-107. https://doi.org/10.1080/17571472.2018.1459226

Mo, F., Zhou, J., Kosinski, M., \& Stillwell, D. (2018). Usage Patterns and Social Circles on Facebook among Elderly People with Diverse Personality Traits. Educational Gerontology, 44(65), 265-275. https://doi.org/10.1080/03601277.2018.1459088

Nigam, C., \& Malik, S. (2018). Social Networking Sites (SNS) Usage and Popularity among 21st Generation Youth: An Empirical Study. International Journal of Emerging Trends in Science and Technology, 4(2), 19-24.

Organ Donor Foundation. (2019).

Padgett, D. K. (2008). Qualitative Methods in Social Work Research (2nd ed.). London: Sage.

Pereira, J. R., Sousa, C. V., Shigaki, H. B. \& Lara, J. E. (2019). Between Social Welfare and Public Power: An Analysis of Social Marketing Strategies for Blood Donation. Brazilian Journal of Marketing, 19(1), 73-85.

Queeley, G. L., \& Campbell, E. S. (2018). Comparing Treatment Modalities for End-Stage Renal Disease: A Meta-Analysis. American Health and Drugs Benefits, 11(3), 118-127. 
Rodriguez-Arias, D., \& Morgan, M. (2016). "Nudging" Deceased Donation Through an Opt-Out System: A Libertarian Approach or Manipulation? The American Journal of Bioethics, 16(11), 25-28. https://doi.org/10.1080/15265161.2016.1222022

Sharif, A., \& Moorlock, G. (2018). Influencing Relatives to Respect Donor Autonomy: Should We Nudge Families to Consent to Organ Donation? Journal of Bioethics, 2018(32), 155-163. https://doi.org/10.1111/bioe.12420

Shava, H., \& Chinyamurindi, W. T. (2018). Determinants of Social Media Usage among a Sample of Rural South African Youth. South African Journal of Information Management, 20(1), a827. https://doi.org/10.4102/sajim.v20i1.827

Shaw, I., \& Holland, S. (2014). Doing Qualitative Research in Social Work. London: Sage. https://doi.org/10.4135/9781473906006

Stiegler, P., Bausys, A., Leber, B., Strupas, K., \& Schemmer, P. (2018). Impact of Melatonin in Solid Organ Transplantation-Is It Time For Clinical Trials? A Comprehensive Review. International Journal of Molecular Sciences, 2018(19), 1-14. https://doi.org/10.3390/ijms19113509

Sukalla, F., Wagner, A. J. M., \& Rackow, I. (2017). Dispelling Fears and Myths of Organ Donation: How Narratives that Include Information Reduce Ambivalence and Reactance. International Journal of Communication, 11, 5027-5047.

Symvoulakis, E.K., Markaki, A., Anyfantakis, D. \& Rachiotis, G. (2018). Organ Donation Awareness: Rethinking Media Campaigns. International Journal of Health Policy Management, 7(12), 1165-1166. https://doi.org/10.15171/ijhpm.2018.85

Taylor, B. J., Killick, C., \& Mcglade, A. (2015). Understanding and Using Research in Social Work. London: Sage. https://doi.org/10.4135/9781473922365

Thomson, D. (2017). Organ donation in South Africa-A Call to Action. South African Journal of Critical Care, 33(2), 36-37. https://doi.org/10.7196/352

Weyers, M. L. (2012). The Theory and Practice of Community Work: A South African Perspective (2nd ed.). Potchefstroom: Keurkopie.

Whittaker, A. (2012). Research Skills for Social Work (2nd ed.). London: Sage.

Williamson, L. D., Reynolds-Tylus, T., Quick, B. L., \& Shuck, M. (2017). African-Americans' Perceptions of Organ Donation: Simply Boils Down To Mistrust. Journal of Applied Communication, 45(2), 199-217. https://doi.org/10.1080/00909882.2017.1288293

Wong, S. H., \& Chow, A. Y. M. (2017). Perceptions of posthumous organ donation base on the theory of reasoned action. Journal of Death and Dying, 75(3), 284-299. https://doi.org/10.1177/0030222816633241

\section{Copyrights}

Copyright for this article is retained by the author(s), with first publication rights granted to the journal.

This is an open-access article distributed under the terms and conditions of the Creative Commons Attribution license (http://creativecommons.org/licenses/by/4.0/). 